\title{
AN OBSERVATIONAL STUDY OF FOLLOW UP OF MDR- TUBERCULOSIS PATIENTS AFTER SUCCESSFUL COMPLETION OF CATEGORY 4 TREATMENT UNDER RNTCP (PMDT) IN ALLAHABAD DISTRICT
}

\author{
Mahmood T'1 \\ ${ }_{1}^{1}$ Professor \& Head, Department of Pulmonary Medicine, MLN Medical College, Uttar Pradesh, India \\ ${ }^{2}$ Final Year Resident, Department of Pulmonary Medicine, MLN Medical College, Uttar Pradesh, India \\ ${ }^{3}$ Associate Professor, Department of Pulmonary Medicine, MLN Medical College, Uttar Pradesh, India \\ ${ }_{4}^{4} 3^{\text {rd }}$ yr Resident, Department of Pulmonary Medicine, MLN Medical College, Uttar Pradesh, India \\ ${ }^{5}$ Senior Resident, Department of Pulmonary Medicine, MLN Medical College, Uttar Pradesh, India
}

\section{ABSTRACT}

Introduction: Drug-resistant TB is a persistent threat, with 490000 million cases of multidrug-resistant TB emerging in 2016. The countries with the largest numbers of MDR/RR-TB cases were China, India and the Russian Federation. Given the prolonged nature of MDR-TB, one might expect higher rates of chronic disability among cured patients with MDR- TB. To explore these questions, we conducted an observational study focusing on: clinical, bacteriological, biochemical and various health parameter status of successfully treated MDR-TB patients.

Methods: Subjects enrolled in study as per inclusion and exclusion criteria were assessed by recording of demographic data and were subjected to a predetermined set of questions for determining the history of previous anti tubercular treatment and exposure to various type of risk factor for development of MDR TB. Physical parameters of health were determined and recorded.

Results: Total of 84 patients were enrolled in our study (57-males, 27 females). 69 subjects (46-males, 23-Females) were found apparently healthy. 25 subjects migrated outside. 6 patients (male-6, Female-2) died.7 patients were diagnosed as XDR-TB (5-Males,2-Females).34 subjects(18- males, 16-females) $(44.73 \%)$ were very under weight. Total 13 (Males-12, Females-1) out of 76 subjects $(17.10 \%)$ were under weight. Mid arm circumference (MAC) of 35 out of 76 (21- males, 18-females) subjects (46.05\%) was below $5^{\text {th }}$ percentile. Majority of subjects showed moderate \& severe obstruction in PEFR.

Conclusion: This study shows that the community based standardized treatment regimen is effective as only one of the patients was bacteriologically positive on follow up. However, significant numbers of treated MDR-TB patients suffer from clinical, nutritional and functional post-treatment adverse events leading to some morbidity.

Keywords:MDR-TB,XDR-TB

\section{INTRODUCTION}

Tuberculosis (TB) is as old as mankind ${ }^{1-3}$ and prevails since antiquity. TB has coevolved with humans for many thousands of years, and

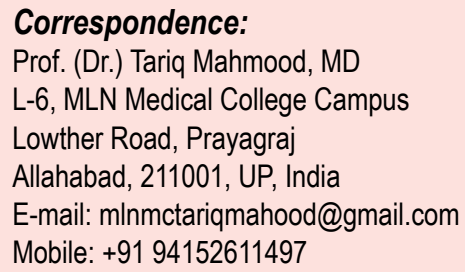

perhaps for several million years ${ }^{7}$ Oldest known human remains showing signs of TB infection are 9000 years old. ${ }^{8}$ TB remains a major global health problem and ranks as the second leading cause of death worldwide, second only to HIVI AIDS, as the greatest killer worldwide due to a single infectious agent. ${ }^{4}$. For the past 5 years, it has been the leading cause of death from a single infectious agent, ranking above HIVIAIDS. ${ }^{5}$ The disease is usually chronic with cardinal features like persistent cough with or without expectoration intermittent fever, loss of appetite, weight loss, chest pain and haemoptysis. ${ }^{6}$ In 2016 , there were 
an estimated 10.4 million cases of tuberculosis with 1.67 million deaths, making tuberculosis the ninth leading cause of death worldwide. ${ }^{9}$ The 2017 WHO Global Tuberculosis Report estimated 490000 cases of multidrug-resistant (MDR) tuberculosis, with less than $50 \%$ survival in patients who received recommended WHO treatment regimens. ${ }^{9-14}$ The Report reveals the dire need for new therapies and approaches for improving tuberculosis treatment delivery and management outcomes. Many challenges remain in developing optimal tuberculosis treatment regimens. ${ }^{15} \mathrm{As}$ per the Global TB Report 2017, ${ }^{16}$ worldwide approximately $4.1 \%$ of new TB patients and 19\% of previously treated TB patients have multidrug resistant-TB (MDR-TB), i.e. TB resistant to at least two of the first-line drugs - isoniazid and rifampicin. Extensively drug resistant TB (XDR-TB), defined as MDR-TB with additional resistance to at least one fluoroquinolone and one second line injectable aminoglycoside drug has been reported by 123 countries. The proportion of XDR-TB among MDRTB patients is $6.2 \%$ worldwide. The estimated number of MDR/rifampicin resistant (RR)-TB in India is 147000 , accounting for one fourth of the global burden of MDR/RR-TB. ${ }^{16}$

Studies in India and other developing countries have focused on various causes and risk factors for default. Gender, alcoholism, treatment after default, poor knowledge of TB, irregular treatment and socio-economic status are some of the factors which have been found to be associated with higher default rates. ${ }^{17-20} \mathrm{Once}$ a drug resistant strain has developed it can be transmitted directly to others. Although there are some studies on follow up status of pulmonary tuberculosis patients, the information on post treatment status of the MDRTB patients successfully treated remains largely unknown and very few reports are available. Given the prolonged nature of MDR-TB, one might expect higher rates of chronic disability among cured patients with MDR- TB compared with those with drug susceptible TB. To explore these questions, we conducted an observational study focusing on consequences due to diseases, its management and other parameters.

\section{MATERIALS AND METHODS}

\section{Ethics}

Institutional ethics committee permission was procured prior to the start of the study. Subjects were found with any co-morbid condition and/or were found deficient in nutrition were given proper treatment and nutrition supplement.

\section{Study design}

This is an observational study of follow up of MDRTB patients after successful completion of Category 4 treatment in Allahabad District conducted over a period from July 2017 to September 2018.

\section{Period of Study}

Study was conducted over a period from July 2017 to September 2018

\section{Subjects}

MDR-TB patients enrolled in DOTS-Plus site (DRTB Centre) of Swaroop Rani Nehru Hospital of Allahabad District for pre treatment evaluation, from March 2013 to March 2015, and successfully completed Category 4 treatment, by second line anti TB drugs.

\section{Case Selection}

All patients aged $>18$ years of either sex who have undergone successful completion of Category 4 treatment under RNTCP, were enrolled in this study as per inclusion and exclusion criteria.

\section{Inclusion criteria:}

1. Patients who gave informed and written consent.

2. Patients aged $>18$ years, who had successfully completed Category 4 treatment, for MDR Pulmonary TB, which was started in the period from March 2013 to March 2015 as per RNTCP criteria.

\section{Exclusion criteria:}

Patients were excluded from the study if they have any of the following conditions:

1. Patients who refused to give consent for participation in study.

2. MDR-TB in extra pulmonary TB patients

3. HIV infection

4. Any connective tissue disorders

5. Any Long-term steroid or cytotoxic drug therapy

\section{Study Protocol}

After obtaining written informed consent, patients qualifying inclusion criteria will be assessed as follows:- 
- Recording of demographic data

- Were subjected to a predetermined set of questions for determining the history of previous anti tubercular treatment and exposure to various type of risk factor for development of MDR TB.

- Physical parameters of health was determined and recorded.

Investigations: Patients will be investigated for following parameters

1. Biochemistry $(\mathrm{Hb}, \mathrm{TLC}, \mathrm{DLC}, \mathrm{S}$. Bilirubin, SGPT, SGOT, S.ALP, S. protein, S. Albumin, S. Globulin, Thyroid profile, HBsAg, AntiHCV S.Urea, S.Creatinine, FPG).

2. Sputum for AFB Smear.

3. PEFR Test

4. Other investigation deemed necessary for any individual patient.

\section{Analysis of Data}

The data will be analysed using appropriate statistical methods.

\section{RESULTS AND OBSERVATION}

Between March (2013) to March (2015) a total of 121 patients were registered in DOTS PLUS centre S.R.N. Hospital Allahabad and declared "successfully treatment completed". Home visit was made to trace 121 subjects with the help of District T.B-HIV coordinator. Out of 121 subjects 112 patients could be currently traced. A Total of 84 subjects reported back to hospital and they were interviewed and investigated for various health parameters and their data was recorded. Thus a Total of 84 patients (57-males, 27 -females) were enrolled and investigated in study. 9 subjects were lost to follow up due to inability to trace the address. 69 of the recorded subjects were found to be apparently healthy. 20 male subjects migrated outside for work. 5 female subjects migrated to their in- law's house after marriage. Hence these 25 subjects (20-males, 5 -females) were interviewed telephonically with set of questions and were found to be apparently healthy. Hence including these subjects, 94 subjects $(69+25)$ out of 112 traced subjects (83.92\%) were found to be apparently healthy. 3 patients were HIV positive and were not included in the study. Total 8 patients out of 84 $(9.5 \%)$ died .6 male patients $(7.1 \%)$ and 2 Female patients $(2.3 \%)$ out of 84 subjects died after successful treatment completion of CAT-4 MDRTB.

Total 7 patients out of $84(8.3 \%)$ were diagnosed as XDR-TB (5-Males (5.9\%), 2-Females (2.3\%) with average duration of 8 months after successful MDR-TB Treatment completion. A Total of 69 $(82.14 \%)$ subjects [ 46 males ( $54.76 \%)$, 23 Females $(27.38 \%)]$ were found apparently healthy. The mean duration of follow up of subjects was 20.56 months with \pm 7.94 S.D. ranging from 6 months to 38 months.

Table 1: Mean \& Median age of the study participants males and females

\begin{tabular}{|l|c|c|}
\hline \multicolumn{1}{|c|}{ AGE } & MEDIAN & MEAN \\
\hline MALES+FEMALES & 25.5 & 29.75 \\
\hline MALES $(\mathrm{M})$ & 25 & 30.75 \\
\hline FEMALES $(\mathrm{F})$ & 26 & 27.62 \\
\hline
\end{tabular}

Table 1 shows that the Median age of all the subjects was 25.5 years Median age for males and females were 25 and 26 years respectively. Mean age with S.D for all subjects were $29.75+/-11.49$. Mean age for males and females were $30.75+/-$ 12.58 and $27.62+/-8.56$ years respectively.

\begin{tabular}{|c|c|c|}
\hline $\begin{array}{l}\text { BODY MASS } \\
\text { INDEX (BMI) }\end{array}$ & MEDIAN & $\begin{array}{l}\text { MEAN +/- } \\
\text { S.D }\end{array}$ \\
\hline MALES+FEMALES & 19.40 & $18.95+/-2.95$ \\
\hline MALES (M) & 19.5 & $19.48+/-2.42$ \\
\hline FEMALES (F) & 16.6 & $17.88+/-3.63$ \\
\hline
\end{tabular}

Table 2 shows that the 34 subjects out of 76 $(44.73 \%)$ were very under weight.18 out of 51 males (35.29\%) and 16 out of 25 females (64\%) were very underweight. Total 13 out 76 subjects (17.10\%), 12 out of 51 males (23.52\%) and 1 out of 25 females (4\%) were under weight. Weight of 29 out of 76 subjects (38.15\%), 21 out of 51 males $(41.17 \%)$ and 8 out of 25 females (32\%) were within normal range. 
Table 3: Median \& Mean MAC of Males and Females in centimetres

\begin{tabular}{|l|c|c|}
\hline $\begin{array}{c}\text { MID-ARM } \\
\text { CIRCUMFERENCE (MAC) }\end{array}$ & MEDIAN & $\begin{array}{c}\text { MEAN +/- } \\
\text { S.D }\end{array}$ \\
\hline MALES+FEMALES & 19.40 & $18.95+/-2.95$ \\
\hline MALES (M) & 19.5 & $19.48+/-2.42$ \\
\hline FEMALES (F) & 16.6 & $17.88+/-3.63$ \\
\hline
\end{tabular}

Table 3 shows that the Median MAC of all the subjects was $24.5 \mathrm{~cm}$. Median MAC of males and females were 26 and $20 \mathrm{~cm}$ respectively. Mean MAC with S.D of all the subjects was $23.98+/-4.27$ $\mathrm{cm}$. Mean MAC with S.D of males and females were $25.62+/-3.57$ and $20.64+/-3.63 \mathrm{~cm}$ respectively.

\begin{tabular}{|c|c|c|c|c|c|c|c|c|}
\hline $\begin{array}{l}\text { AGE } \\
\text { GROUP }\end{array}$ & $\begin{array}{l}\text { BEL } \\
5^{\text {th }} \\
\text { cen }\end{array}$ & & $\begin{array}{l}5^{\text {th }} p e \\
\text { centi }\end{array}$ & & $\begin{array}{l}15^{\text {th }} \\
\text { cent }\end{array}$ & & & \\
\hline \begin{tabular}{|l|} 
GENDER \\
\end{tabular} & $M$ & $\mathrm{~F}$ & $M$ & $\mathrm{~F}$ & $M$ & $\mathrm{~F}$ & $M$ & $\mathrm{~F}$ \\
\hline \begin{tabular}{|l|}
$18-19$ \\
\end{tabular} & 0 & 2 & 1 & 1 & 2 & 0 & 1 & 0 \\
\hline \begin{tabular}{|l|}
$20-24$ \\
\end{tabular} & 8 & 6 & 4 & 2 & 4 & 0 & 0 & 1 \\
\hline $25-34$ & 6 & 7 & 7 & 2 & 4 & 1 & 0 & 0 \\
\hline $35-44$ & 3 & 2 & 1 & 1 & 2 & 0 & 1 & 0 \\
\hline $45-54$ & 2 & 0 & 5 & 0 & 0 & 0 & 0 & 0 \\
\hline $55-64$ & 2 & 0 & 0 & 0 & 0 & 0 & 0 & 0 \\
\hline $65-74$ & 0 & 0 & 1 & 0 & 0 & 0 & 0 & 0 \\
\hline
\end{tabular}

Table 4 shows that the Mid -arm circumference (MAC) of 35 out of 76 subjects (46.05\%) was below $5^{\text {th }}$ percentile.MAC of 21 out of 51 males $(41.17 \%), 18$ out of 25 females (72\%) were below $5^{\text {th }}$ percentile.MAC of 12 out of 51 males (23.52\%) was in $15^{\text {th }}$ percentile and 1 out of 25 females (4\%) were in $15^{\text {th }}$ percentile.

Table 5: Mean and Median PEFR of subjects in litres per minute $(I / \mathrm{min})$

\begin{tabular}{|l|l|l|}
\hline PEFR & MEDIAN & MEAN+/-S.D \\
\hline MALES+FEMALES & 300 & $299.86+/-99.10$ \\
\hline MALES & 315 & $321.20+/-88.21$ \\
\hline FEMALES & 260 & $267.91+/-91.37$ \\
\hline
\end{tabular}

Table 5 shows that the Median PEFR of all subjects was $300 \mathrm{l} / \mathrm{min}$ and mean PEFR with S.D was 299.86+/-99.10 $\mathrm{l} / \mathrm{min}$.Median PEFR of males was $315 \mathrm{l} / \mathrm{min}$ and mean PEFR with S.D was $321.20+/-$ $88.91 \mathrm{l} / \mathrm{min}$.Median PEFR of females was $260 \mathrm{l} /$ min and mean PEFR with S.D was $267.91+/-91.73$ $1 /$ min.

\begin{tabular}{|c|c|c|}
\hline \multicolumn{3}{|c|}{$\begin{array}{l}\text { Table 6: Observed percentage of predicted PEFR } \\
\text { of subjects }\end{array}$} \\
\hline $\begin{array}{l}\text { OBSERVED \% OF } \\
\text { PREDICTED PEFR }\end{array}$ & MALES & FEMALES \\
\hline$<33 \%$ & 5 & 1 \\
\hline $33 \%-50 \%$ & 10 & 7 \\
\hline $50 \%-80 \%$ & 32 & 8 \\
\hline$>80 \%$ & 3 & 9 \\
\hline
\end{tabular}

Table 6 shows that 32 males and 8 females had moderate obstruction (observed PEFR values between $50 \%$ to $80 \%$ ). 10 males and 7 females had severe obstruction (their observed percentage of PEFR values between 33\% to 50\%).9 females and 3 males had their observed percentage of PEFR values more than $80 \%$ (mild obstruction). 5 males and 1 female had their observed percentage of PEFR values less than $30 \%$ (very severe obstruction).

No of subjects with increased:

- Serum urea $\quad-8$

- Serum Creatinine - 6

- Serum Bilirubin - 36

- Serum SGOT - 13

- Serum SGPT -12

- TSH $\quad-4$

No of patients with decreased

$\begin{array}{ll}\text { - Serum Protein } & -17 \\ \text { - Serum Albumin } & -16 \\ \text { - Serum Globulin } & -2\end{array}$

Table 7: Mean with SD of various biochemical parameters

\begin{tabular}{|l|l|}
\hline BIOCHEMICAL PARAMETERS & MEAN +/- S.D \\
\hline Haemoglobin & $13.13+/-2.18$ \\
\hline Total Leucocyte Count & $8054.21+/-3109.88$ \\
\hline Fasting Plasma Sugar & $94.66+/-14.37$ \\
\hline HbA1C & $5.43+/-0.601$ \\
\hline Serum Bilirubin & $0.876+/-0.42$ \\
\hline Serum SGOT & $29.90+/-12.53$ \\
\hline Serum SGPT & $29.93+/-16.29$ \\
\hline Serum Protein & $6.73+/-1.05$ \\
\hline Serum Albumin & $3.98+/-0.63$ \\
\hline Serum Globulin & $2.90+/-0.59$ \\
\hline Serum TSH & $2.24+/-1.49$ \\
\hline Serum T4 & $1.35+/-0.33$ \\
\hline Serum T3 & $2.73+/-0.65$ \\
\hline Serum Urea & $28.79+/-11.50$ \\
\hline Serum Creatinine & $0.79+/-0.39$ \\
\hline &
\end{tabular}




\section{Socio-demographic Data}

Out of 84 subjects 46 were married (32-Males, 14-Females) and 38 were unmarried (26-Males, 12-Females). Out of 84 subjects, 20 were Graduate, 15 were intermediate pass, 15 were high school pass, 11 passed primary school and 14 were illiterate. History of ATT intake before the initiation of cat 4 treatment: Out of 76 subjects, 39 took from Government, 26 from Private health facility and 9 took from both Government and Private health facility. 9 out of $77(11.68 \%)$ subjects had h/o contact with drug resistant TB (Primary MDRTB). 1 out of 9 was diagnosed XDR and 8 were apparently healthy after successful cat 4 treatment.

Before initiation of CAT-4 MDR treatment number of patients out of 76 who took ATT regularly was 48 and number of patients who took ATT irregularly were 28.

Number of subjects who were

- Tobacco chewers - 23

- Smokers - 11

- Alcoholics $\quad-10$

\section{DISCUSSION}

With current short course chemotherapy (SCC) regimens, majority of the patients with tuberculosis are cured of the disease. However, the information regarding the long term sequelae remains largely unknown. Studies have documented that $30-47 \%$ of cured pulmonary TB patients continue to have respiratory symptoms at the end of treatment, $(40 \%)$ after one year of treatment and $(15.9 \%)$ after two and a half years after treatment. ${ }^{21-24}$

The mean (+S.D.) age of study done by Neeta Singla, Rupak Singla et al ${ }^{25}$ patients was $33.5+11$, the age ranging from 15-69 years. Thirty five were men and 28 were women. In our study the mean (+/-S.D) age was 29.92(+/-11.79) the age ranging from 18-67.Fifty seven were men and 27 were women.In our study three patients were found to be HIV positive. In study done by Neeta Singla, Rupak Singla et al. there were no HIV positive patients ${ }^{25}$

Twenty three $(40 \%)$ of the patients had a normal Body Mass Index, 16 (34\%) were underweight and $8(17 \%)$ patients were found to be overweight in study done by Neeta Singla,Rupak Singla et al. In our study 34 subjects out of $76(44.73 \%)$ were very under weight.18 out of 51 males (35.54\%) and 16 out of 25 females (64\%) were very under weight. Total 13 out 76 subjects (17.10\%), 12 out of 51 males (23.52\%) and 1 out of 25 females (4\%) were under weight. Weight of 29 out of 76 subjects (38.15\%), 21 out of 51 males (41.17\%) and 8 out of 25 females (32\%) had their weight within normal range.

Due to its prolonged nature, treated patients of MDR-TB are expected to have higher rates of chronic disability compared with those with drug susceptible TB. However, only few reports are available in the literature who have studied the post-treatment sequelae of MDR-TB patients . ${ }^{26-27}$

A recent study from India ${ }^{24}$ among new drug susceptible TB patients treated with first line anti tuberculosis drugs observed that $14-18$ years after treatment completion 29\% participants had persistent respiratory symptoms, $86 \%$ had radiological sequelae and lung functions impairments were present in $65 \%$ of the patients. This again emphasizes the point that post treatment sequelae are more common among MDR-TB patients compared to drug susceptible TB patients. However a study from Peru followed 120 MDR-TB patients for a median 67 (47-88) months after initiation of treatment and reported favourable long-term outcome among $71 \%$ of patients.

In our study also most of the subjects, 94 subjects out of 121 traced were apparently healthy and were able to resume their work.

In our study 69 subjects were apparently healthy and only one was bacteriologicaly positive.In study done by Neeta Singla, Rupak Singla et $a^{25}$ none of the currently alive 51 patients was bacteriologicaly positive on follow up.The findings are similar to study from Peru where 4 years after initiation of MDR-TB treatment only one out of 86 cured patients relapsed.$^{28}$ However another study from Taiwan reported a relapse rate of $6.5 \%$ among 153 MDR-TB patients who were followed up for 6 years after cure. ${ }^{27}$

Though our study was on the patients who successfully completed treatment of cat 4 MDRTB, 8 patients died and 7 diagnosed as XDR within first year of follow up hence it indicates that there is requirement of close follow up within first year of successful cat 4 MDR-TB treatment completion. 
In study done by Neeta Singla, Rupak Singla et al ${ }^{25}$ among 63 traced patients mortality rate was $19 \%$. Among 53 cured patients, 5 died, and among 9 patients who defaulted, 6 died. One patient considered as treatment failure subsequently died of TB. Thus mortality was more common among patients who default or fail to treatment compared to those who were successfully treated. Another study from Peru also reported higher mortality during follow up among MDR-TB patients who defaulted or failed during treatment. ${ }^{28}$ In our study 8 patients out of $112(7.1 \%)$ traced patients died.

In Neeta singla, Rupak single et al study Body Mass Index, 16 (34\%) were underweight .In our study majority of patients had decreased percentile of mid arm circumference as per their age and decreased serum protein and albumin.44.73\% patient were very under weight and $17.10 \%$ were under weight. It clearly indicates that there is need of protein supplementation during treatment and also after completion of cat 4 MDR-TB treatment.

In our study 32 males and 8 females had moderate obstruction (observed percentage of predicted PEFR values between $50 \%$ to $80 \%$ ). 10 males and 7 females had severe obstruction (their observed percentage of predicted PEFR values between $33 \%$ to $50 \%) .9$ females and 3 males had their observed percentage of predicted PEFR values more than $80 \%$ (mild obstruction). 5 males and 1 female had their observed percentage of predicted PEFR values less than $30 \%$ (very severe obstruction). Though the PEFR measurement is crude method to measure pulmonary function, in our study we found that there is significant pulmonary dysfunction occurring as post-tubercular sequelae.

In our study though HIV positive patients were not included but it was observed they had no adverse follow up (no death, no XDR).

The major limitation of this study is that of the target 121 patients under study only 84 were investigated and recorded. Many were lost due to migration and $7.4 \%$ due to inability to trace the address. Another limitation was small number of patients.

Another limitation of this study is that the observations made need not be due to MDR-TB sequelae alone and could be due to other health related factors in some of the study population.

\section{CONCLUSION}

The current observational study has shown that the community based standardized treatment regimen is effective as only one of the patients was bacteriologicaly positive on follow up.

However significant number of treated MDRTB patients suffer from clinical, nutritional and functional post-treatment adverse events leading to some morbidity.

These issues need to be addressed preferably under the programme guidelines itself.

The post-treatment pulmonary rehabilitation of MDR-TB patients should be an integral part of DOTS Plus programme and will improve the impact of the National programme in the community.

Further research studies are recommended as very little studies are done on follow up of patients of successfully completed category 4 MDR-TB treatment. There is need to expand the limited knowledge and to create effective interventions with an objective to decrease the suffering from clinical, nutritional and functional post treatment adverse events and morbidity.

\section{CONFLICT OF INTEREST}

None

\section{REFERENCES}

1. Mohan A, Sharma SK. Epidemiology. In: Sharma SK, Mohan A, editors Tuberculosis. New Delhi: Jaypee Brothers Medical Publishers; 2001 p. 1429.

2. Sharma SK, Mohan A. Multidrug-resistant tuberculosis.Mediquest1995;13:1-11.

3. Mohan A, Sharma SK. History. In: Sharma SK, Mohan A, editors. Tuberculosis. New Delhi: Jaypee Brothers Medical Publishers; 2001 p. 5-13.

4. World Health Organization.Tuberculosis fact sheet. Available from URLhttp://www.who.int/gtb/ publications/factsheet/index.htm

5. World Health Organization. Global tuberculosis report2015. Geneva:WHO;2015htp://apps.who.int/ iris/bitstream/10665/191102/1/9789241565059_ eng.pdf, accessed 2 August 2017). 
6. Park K. Park's Textbook of Preventive and Social Medicine. 20th ed. Jabalpur (India): BanarsidasBhanot; 2009. P. 159.

7. Gutierrez MC, Brisse S, Brosch R, Fabre M, Omais $B$, Marmiesse $M$ et al. Ancient origin and gene mosaicism of the progenitor of Mycobacterium tuberculosis. PLoSPathog

8. Hershkovitz I, Donoghue 2005 Sep;1(1):e5. HD, Minnikin DE, Besra GS, Lee OY, Gernaey AM et al. Detection and molecular characterization of 9000-year-old Mycobacterium tuberculosis from a neolithic settlement in the eastern mediterranean. PLOS ONE 2008;3(10):e3426.

9. WHO. Global tuberculosis report, 2017. Geneva: World Health Organization, 2017.

10. Ahmad Khan F, Salim MAH, du Cros P, et al. Effectiveness and safety of standardised shorter regimens for multidrug-resistant tuberculosis: individual patient data and aggregate data metaanalyses. Eur Respir J 2017; 50: 1700061.

11. Mitnick CD, White RA, Lu C, et al. Multidrugresistant tuberculosis treatment failure detection depends on monitoring interval and microbiological method. Eur Respir J 2016; 48: 1160-70.

12. Dheda K, Limberis JD, Pietersen E, et al. Outcomes, infectiousness, and transmission dynamics of patients with extensively drug-resistant tuberculosis and home-discharged patients with programmatically incurable tuberculosis: a prospective cohort study. Lancet Respir Med 2017; 5: 269-81.

13. Günther $G$, Lange $C$, Alexandru S, et al. Treatment outcomes in multidrug-resistant tuberculosis. $N$ Engl J Med 2016; 375: 1103-05.

14. Zignol M, Dean AS, Falzon D, et al. Twenty years of global surveillance of antituberculosis-drug resistance. N Engl J Med 2016;375: 1081-89.

15. Zumla A, Abubakar I. Clinical trial research in focus: overcoming barriers in MDR-TB clinical trials. Lancet Res pir Med 2017;5: 247-48

16. Global Tuberculosis Report 2016. Geneva: World Health Organization (www.who.int/tb/publications/ global_report, accessed 19 December 2017).

17. Menon PMPS. Pulmonary TB. India: National Book Trust; 1999. P. 2313-15.

18. Khatri G.R.The Revised National TB Control Programme. A status Report on First 5,00,000 patients. Ind J Tub 1999;46:157-66.
19. Govt. of India. TB India 2001, RNTCP Status Report. New Delhi: DGHS, Govt. ofIndia; 2001.

20. Park K. Park's Textbook of Preventive and Social Medicine. 17th ed. Jabalpur (India):Banarsidasbhanot; 2002. P-138-52 and 312-14.

21. Rajeswari $R$, Muniyandi $M$, Balasubramanian $R$, and Narayanan PR. Perceptions of tuberculosis patients about their physical, mental and social well-being: a field report from South India. Soc Sci Med 2005; 60: 1845-53.

22. Muniyandi $M$, Rajeswari $R$, Balasubramanian R, Nirupa C, Gopi PG, Jaggarajamma K et al. Evaluation of posttreatment health-related quality of life (HRQoL) among tuberculosis patients. Int $J$ Tuberc Lung Dis 2007;11:887-92.

23. Sophia Vijay, Balasangameswara VH., Jagannatha PS, Saroja VN, Kumar P. Treatment outcome and two \& half years follow-up status of new smear positive patients treated under RNTCP. Indian $J$ Tuberc 2004; 51:199-08.

24. Banu Rekha $V$ V, Rajeswari $R$, Kuppu Rao K V, Rahman F, Adhilakshmi A R, Kalaiselvi D, Murugesan P, Sundaram Vand Narayanan P R. Assessment of long term status of sputum positive pulmonary TB patients successfully treated with short course chemotherapy. Indian J Tuberc 2009;56:132-40

25. Post treatment sequelae of multi-drug resistant tuberculosis patients neeta Singla, Rupak Singla, Sheron Fernandes and Digamber Behera: [Ind $J$ Tuberc 2009; 56: 206-212] 85. Shin, SS, Furin, JJ, Alcantara F, Bayona, J, Sanchez, E,Mitnick CD. Long-term follow- up for multidrug-resistant tuberculosis. Emerging Infectious Diseases 2006;12: 687-88.

26. Avendano M; Goldstein R S. Multidrug-resistant tuberculosis: long term follow-up of 40 non-HIVinfected patients. Can Respir J 2000; 7: 383-9.

27. Fletcher CM, Elmes, PC, Wood, $\mathrm{CH}$. The significance of respiratory symptoms and the diagnosis of chronic bronchitis in a working population. BMJ 1959; 2: 257-66.

28. Shin, SS, Furin, JJ, Alcantara F, Bayona, J, Sanchez, E,Mitnick CD. Long-term follow- up for multidrug-resistant tuberculosis. Emerging Infectious Diseases 2006;12: 687-88. 